\title{
Fetal mummification in the major domestic species: current perspectives on causes and management
}

This article was published in the following Dove Press journal:

Veterinary Medicine: Research and Reports

8 June 2015

Number of times this article has been viewed

\author{
Réjean C Lefebvre \\ Department of Clinical Sciences, \\ Theriogenology, Faculté de Médecine \\ Vétérinaire, Université de Montréal, \\ Saint-Hyacinthe, QC, Canada
}

\begin{abstract}
Fetal mummification is an uncommon condition in most domestic species. While most often seen in multiparous and polytocous species like swine, it is also observed in monotocous species when the fetus is retained for a long time. The low prevalence of the condition may help explain the scarcity of information in the literature. To further complicate the study of this phenomenon, the physiological mechanisms that maintain pregnancy vary between species, implying different pathways for the condition. The exact outcome of early fetal mortality is unpredictable, and is influenced by several factors, including the cause of fetal mortality, differences in pregnancy between species, stage of gestation at fetal death, and number of fetuses. Based on our current knowledge of natural fetal mummification events, there are a number of prerequisites for the process of fetal mummification to occur. Examining the circumstances associated with fetal mummification can help scientists better understand the etiology and clinical situation in different species. The objective of this article is to review fetal mummification in the major domestic species: cattle, goats, sheep, horses, swine, dogs, and cats. This paper discusses the clinical situation, the most common and important etiologies, and the treatment approaches for restoring future pregnancy in the female, and where applicable, herd fertility.
\end{abstract}

Keywords: mummification, fetus, domestic species

\section{Introduction}

Failure of pregnancy is usually divided into stages based on the fetus's development and potential viability: embryonic mortality and fetal mortality. The exact outcome of early fetal mortality is unpredictable and influenced by several factors, such as the cause of the fetal mortality, species differences, stage of gestation at fetal death, and number of fetuses. One possible outcome of fetal death is mummification. Fetal mummification is occasionally diagnosed in many domestic species, including the cow, ${ }^{1}$ sheep, ${ }^{2}$ goat, ${ }^{3}$ horse,${ }^{4}$ swine,${ }^{5}$ dog, and cat, ${ }^{6}$ with the highest prevalence occurring in the swine (Table 1). ${ }^{7}$ While most often found in multiparous species, it can also occur in monotocous ones when the fetus is retained for a long time. The low prevalence of the condition may explain the scarcity of information in the literature.

In nature, a number of environmental conditions can lead to mummification: drought (deserts), oxygen depletion (peat bogs), and ice (glaciers). The mummification process stops autolysis, more commonly known as decomposition. Autolysis involves two steps: 1) the release of digestive enzymes normally present in organs like the intestine and liver, and 2) the breakdown of organic matter by bacteria, or putrefaction. When conditions become too dry and the oxygen concentration too low, bacteria cannot survive and the body fails to decompose. The dehydration of
Correspondence: Réjean C Lefebvre Department of Clinical Sciences, Theriogenology, Faculté de Médecine Vétérinaire, Université de Montréal, 3200 rue Sicotte, Saint-Hyacinthe, QC J2S 7C6, Canada Email rejean.lefebvre@umontreal.ca (c) (i) (9) 2015 Lefebrre. This work is published by Dove Medical Press Limited, and licensed under Creative Commons Attribution - Non Commercial (unported, v3.0) License. The full terms of the License are available at http://creativecommons.org/licenses/by-nc/3.0/. Non-commercial uses of the work are permitted without any further Dove Medical Press Limited, provided the work is properly attributed. Permissions beyond the scope of the License are administered by Dove Medical Press Limited. Information on how to request permission may be found at: http://www.dovepress.com/permissions.php 
Table I Reported causes of fetal mummification in the major domestic species

\begin{tabular}{ll}
\hline Species & Causes (infectious or noninfectious) \\
\hline Cattle & BVD infection, trichomoniasis \\
Horses & Twinning $^{4}$ \\
Swine & Parvoviral infection \\
Dogs & Canine herpesvirus infection $^{6}$ \\
Cats & Uterine torsion/ectopic pregnancy $^{6}$ \\
Sheep/goat & Toxoplasmosis, Chlamydophila $^{2,3}$ \\
\hline
\end{tabular}

Abbreviation: BVD, bovine viral diarrhea.

tissues is also an important element in the mummification process: when the tissue water content drops below a critical threshold, bacterial putrefaction is inhibited, tissues become desiccated, and the body shrivels to a dry leathery mass of skin, tendons, and bones. ${ }^{8}$

Based on our current knowledge of natural mummification, there are a number of events that must be present in order for fetal mummification to occur: 1) the fetus must die after the development of bones is complete (otherwise autolysis occurs rapidly, and soft tissues are reduced to their basic elements before being absorbed through the endometrium), 2) uterine and fetal fluids must be resorbed relatively rapidly, 3 ) there must be no oxygen in the uterus until the mummification process is complete, and 4) there must be no bacteria in the uterus. Regarding the fourth point, normally the cervix is closed to prevent the entry of putrefactive organisms present in the vagina and vestibule. In addition, the endometrium is intact, and so blocks the entry of organisms potentially present in the vascularization. ${ }^{9}$

The entire process of mummification takes several weeks, depending on the age of the fetus at the time of death. Once all fluids are completely resorbed, the fetal membranes and uterine wall adhere closely to the fetus, and the whole mass becomes brownish black, leathery in appearance, and odorless. It may or may not have some exudate resulting from the degeneration of red blood cells. Mummification that produces a dry, stiff fetoplacental unit with no exudate is called papyraceous mummification, and has been reported in dogs, cats, cattle, buffalo, and sharks. ${ }^{10-15}$ In the other type of mummification, known as hematic or chocolate mummification, a viscous adhesive material covers the mummified fetus. This type has been reported in cattle, buffalo, and dogs. ${ }^{16}$

Fetal mummification is to be differentiated from fetal maceration, in which the fetus putrefies, in the uterine cavity, in the presence of bacteria and oxygen originating from the open cervix. At least at the beginning of the process, mummification requires the continued presence of progesterone from a persistent corpus luteum (CL), (eg, cows), a functional placental (eg, horses), or some exogenous source of progesterone to keep the uterus quiescent. ${ }^{17}$
Although fetal mummification has been described as a clinical sign of certain underlying conditions (Table 2), in both case reports published in the literature and in veterinary textbooks, researchers still do not fully understand the specific mechanism involved. Why, for example, are mummies maintained in the uterus for varying lengths of time when the cervix is partially open and pregnancy-maintenance mechanisms have already been removed? Why is the fertility of the mother not always affected following fetal mummification? What is the exact mechanism of water absorption (fetus and membranes) during mummification?

\section{Cattle Prevalence}

Mummification of bovine fetuses has an incidence of less than $2 \%{ }^{1}$ Breed and previous occurrence are risk factors, with a higher incidence of fetal mummification in Guernsey and Jersey cattle. A higher risk of recurrence (30\%) in cows that have experienced a similar event in a previous gestation has been reported. ${ }^{17}$ This has not been observed for other species, although the scarcity of the condition makes any critical assessment of recurrence difficult. In cattle, fetal mummification occurs after 70 days of gestation, the time of fetal ossification. Mummification occurs most often between the 3rd and 8th month of gestation, without any concomitant luteolysis of the CL or opening of the cervix. The long, hard cervix has three or four complex circular folds, and is less responsive to endocrine changes. Fetal mummification associated with a persistent CL is observed mainly in cattle and goats. Note that both species are dependent on progesterone $\left(\mathrm{P}_{4}\right)$ produced by the CL for the maintenance of pregnancy. ${ }^{8}$ In cattle, however, the placenta is capable of producing sufficient $\mathrm{P}_{4}$ to maintain pregnancy between days 150 and 200 of gestation. ${ }^{18}$ After fetal death, the amniotic and allantoic fluids are resorbed, dehydrating the fetal tissues and annex membranes. Eventually, the caruncles disappear during the dehydration process. The longer the mummified fetus is retained, the dryer, firmer, and more leathery the tissues of the fetus become.

\section{Etiology}

Several potential causes for this condition have been proposed: bovine viral diarrhea (BVD), leptospirosis and mold,

Table 2 Prevalence of fetal mummification among species, from highest to lowest

Swine $>$ small ruminants (goats and sheep) $>$ cattle $>$ cats and dogs $>$ horses

Note: This order of prevalence is based on the sparse literature for the major domestic species. 
Neospora caninum: ${ }^{19,20}$ mechanical factors, such as compression and/or torsion of the umbilical cord; ${ }^{21}$ uterine torsion; ${ }^{22}$ defective placentation; ${ }^{23}$ genetic anomalies; ${ }^{19,24}$ abnormal hormonal profiles; and chromosomal abnormalities. ${ }^{17}$ However, a definitive etiology is rarely established, because of tissue degeneration. The mummification process usually makes bacterial and viral analysis, biopsy, and chromosome analysis a futile exercise. ${ }^{25}$ Deoxyribonucleic acid (DNA) extracted from mummified fetuses revealed that two of ten were carriers (heterozygous) of the autosomal-recessive gene for deficiency of uridine monophosphate synthase (DUMPS), ${ }^{26}$ which is known to contribute to embryonic and fetal mortality in cattle. ${ }^{27}$ There is possibility that sex-linked genes may play a role in fetal mummification. ${ }^{20}$ In a study of maiden Jersey heifers experimentally infected with BVD, $17 \%$ showed fetal mummification. ${ }^{28}$ Ghanem et al detected N. caninum by polymerase chain reaction (PCR) in $25 \%$ of the studied bovine mummified fetuses $(n=15) .{ }^{20}$ Because of the lack of clear evidence, BVD and $N$. caninum as a cause of mummification remains speculative.

\section{Clinical findings}

A majority of diagnoses of suspected mummification (63\%) are established by veterinarians after the farmer notices that the cow's abdomen is unusually small for the given stage of pregnancy. ${ }^{29}$ This finding is in line with the findings of Wenkoff and Manns, who found that mummies stayed in utero until they were removed, with the presenting complaint usually occurring several days past the calving date. ${ }^{30}$ Therefore, no significant systemic or other type of illness is observed in cows except for spontaneous abortion, which may or may not occur.

\section{Diagnosis}

The diagnosis of fetal mummification is generally uncomplicated. Transrectal palpation and ultrasonographic examination show the mummified fetus as a compact, firm, and immobile mass without placental fluid or placentomes. The ultrasound examination reveals the absence of a heartbeat. The general physical examination of the dam appears normal, although decreased milk production and weight loss have been observed in rare cases (but may have been attributable to other factors). ${ }^{31}$

\section{Treatment}

There is a systematic approach to treating pregnant cows diagnosed with fetal mummification (Figure 1). Prostaglandins $\left(\mathrm{PGs} ; \mathrm{PGF}_{2 \alpha}\right)$ are the primary and most effective treatment (25 mg, dinoprost tromethamine [Lutalyse ${ }^{\circledR}$ ]; Zoetis, Montreal, Canada). ${ }^{30}$ In most cases, the mummified fetus will then be expelled from the uterus. All treated cows should be assessed via transrectal and vaginal examination about 5 days after the first injection of $\mathrm{PGF}_{2 \alpha}$, in order to check for the presence of CL, cervical dilation, and the fetus in the vagina. After expulsion of the fetus, a uterine lavage should be performed to remove fetal and placental debris, and the cow should be rapidly induced into estrus and inseminated. In the absence of a treatment response, the most cost-effective option is then to proceed with a second injection of $\mathrm{PGF}_{2 \alpha}$,

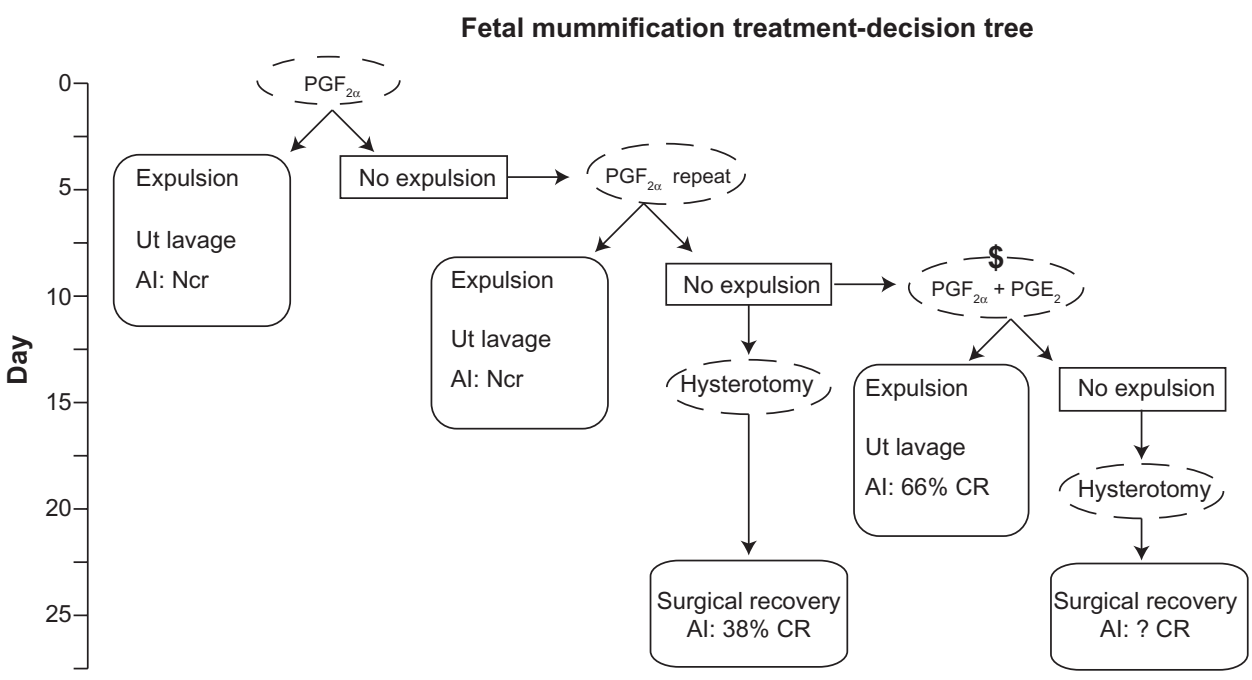

Figure I Decision tree for clinical approaches to fetal mummification in cows.

Note: Reproduced from Lefebvre RC, Saint-Hilaire E, Morin I, et al. Retrospective case study of fetal mummification in cows that did not respond to prostaglandin F2 treatment. The Canadian Veterinary Journal. 2009;50:71-76. ${ }^{29}$

Abbreviations: $\mathrm{Al}$, artificial insemination; $\mathrm{Ncr}$, normal conception rate; Ut, uterine; $\mathrm{CR}$, conception rate; ?, unknown; $\mathrm{PGF}_{2 \alpha}, \mathrm{Prostaglandin}_{2 \alpha}$; $\mathrm{PGE}$ : prostaglandine $\mathrm{E}_{2} ; \$$, expensive. 
followed by the same procedure used following the first treatment. If the cow does not respond to the second injection of $\mathrm{PGF}_{2 \alpha}$ after 5 days, a decision must be made: proceed with an hysterotomy (laparotomy or colpotomy) or continue medical treatment with a combination of $\mathrm{PGF}_{2 \alpha}$ and $\mathrm{PGE}_{2}$. This decision is based on cost-effectiveness and on-farm feasibility (Figure 1).

In one study, a low parturition rate was reported with a single dose of $\mathrm{PGF}_{2 \alpha}$, even though relaxation of the birth canal was satisfactory, suggesting a uterine contractility defect. ${ }^{32}$ In another study, in situations where PGF $_{2 \alpha}$ did not lead to the expulsion of the mummified fetus, a different medical approach was used: mummified fetuses (six of six) were expelled after combination treatment with $\mathrm{PGF}_{2 \alpha}$ (600 mg D-cloprostenol intramuscularly [IM; Estrumate ${ }^{\circledR}$ ]; Merck, Bern, Switzerland) and $\mathrm{PGE}_{2}$ (2.5 dinoprostone intravenously [Endocur ${ }^{\circledR}$ ]; Bern, Switzerland) for a period of 3-6 days. ${ }^{33}$ In addition to their luteolytic properties, ${ }^{34} \mathrm{PGF}_{2 \alpha}$ and $\mathrm{PGE}_{2}$ have a direct effect on myometrial contractility. ${ }^{35-37}$ For cows in good condition, the combined administration of $\mathrm{PGF}_{2 \alpha}$ and $\mathrm{PGE}_{2}$ resulted in more effective uterine contractions than the injection of $\mathrm{PGF}_{2 \alpha}$ alone. ${ }^{38}$ The synergistic effect of both PGs may explain the increased success rate relative to the use of $\mathrm{PGF}_{2 \alpha}$ alone. Estrogens may also be effective, because they relax the cervix and pelvic ligaments, although they tend to change conformation ${ }^{39,40}$ and seem not as good as maintaining normal fertility. ${ }^{29}$ However, the high cost of treatment $\left(\mathrm{PGF}_{2 \alpha}\right.$ and $\mathrm{PGE}_{2}$, greater than US\$250), difficulty in obtaining the drugs, and a scarcity of evidence for their efficacy means this treatment protocol is not widely used.

Depending on the circumstances, hysterotomy may result in a pregnancy rate comparable to that of the rest of the herd. Of course, in the situation where combined treatment with PGs $\left(\mathrm{PGF}_{2 \alpha}\right.$ and $\left.\mathrm{PGE}_{2}\right)$ is not effective or possible, the veterinarian must proceed with a hysterotomy.

Different surgical treatments are available for removing mummified fetuses that cannot be expelled by PG injections. Both hysterotomy via a colpotomy approach ${ }^{24,41}$ and laparotomy via a caudal flank approach have been used as a last resort. ${ }^{42}$ In both cases, access to the pregnant horn is difficult. In the case of colpotomy, this is due to a lack of space in the vagina for manipulating the uterine horn containing the mummified fetus. With the caudal flank approach, the distance from the uterine horn to the caudal abdominal wall and the thickness of the abdominal wall may limit the surgeon's ability to exteriorize the uterus. The colpotomy approach is not recommended for large mummies. ${ }^{24}$ In one study, access to the pregnant horn was improved by using a tocolytic agent (ritodrine), which facilitated the exteriorization of the mummy by relaxing the uterine tract. ${ }^{43}$ Fifty percent of surgeries in this study (five of ten) required the use of a tocolytic agent. To reach the most economically sound decision, the impact of surgical versus medical treatment on milk production also has to be taken into consideration.

\section{Prognosis}

Medical and surgical approaches both result in a normal pregnancy rate..$^{29}$ In cows with a history of fetal mummification, histological assessment has shown an intact epithelium and preserved uterine glands with no sign of inflammation. ${ }^{31}$

\section{Prevention}

Due to the absence of specific causes associated with fetal mummification, it is important to maintain good sanitary conditions and a vaccination program. A rigorous reproductive monitoring program is also important.

\section{Small ruminants (goats and sheep) Prevalence}

In does and ewes, fetal mummification is uncommon, and affects both single and twin fetuses. It is associated with four major conditions: toxoplasmosis, Chlamydophila, border disease, and Coxiella (ToxChBCox) infection. ${ }^{44}$ The prevalence of each of these is difficult to estimate, because diagnostic samples are often not submitted for testing, serologic results are not specific, infected females are usually asymptomatic, these diseases are generally sporadic in incidence, and abortion storms are rare. However, goats and sheep seem to present a higher prevalence of fetal mummification than cows.

\section{Etiology}

Compared to cows, fetal mummification in does and ewes is most often associated with infectious diseases, in particular ToxChBCox. Of these infectious agents, Coxiella infection is at the top of the differential diagnosis list. Energy and protein deficiencies, particularly on days $90-120$ of gestation, have also been implicated..$^{45}$ However, information in the literature is scarce.

Unlike border disease, Chlamydophila abortus, Coxiella burnetii, and Toxoplasma gondii are zoonotic agents. In most cases, primiparous females are more susceptible than multiparous animals. The transmission route is oronasal contact with the infectious agent in aborted tissue (placenta), vaginal discharge, or a contaminated neonate. With Chlamydophila infection, pigeons and sparrows may 
serve as the reservoir, and researchers have speculated that ticks and insects may also play a role in transmission. ${ }^{44}$ For C. burnetii, cattle, sheep, goats, dogs, and birds may serve as carriers. Ticks (multiple species) are the primary natural reservoir for Coxiella, and are probably responsible for the disease being transmitted to domestic animals. Unlike the other diseases, C. burnetii may cause abortion in successive parturitions. For T. gondii, cats are the definitive host for the disease, and small ruminants can be infected by oronasal contact with the urine and feces of infected adults or newborns.

\section{Clinical signs}

Contrary to cows and mares, mummified fetuses in small ruminants are spontaneously aborted. Infected females with a ToxChBCox are usually asymptomatic (all systems), and the diseases are sporadic in occurrence. When first infected, the female sometimes has a short and transient mild fever or malaise that is usually not noticed by the farmer. Spontaneous abortion is observed in about $5 \%$ of females in flocks with the endemic form of the disease, and greater than $20 \%$ in the epidemic situation (uncommon). ${ }^{45}$ Abortion, stillbirth, and fetal maceration and mummification are usually observed when infection occurs at the end of the second trimester and during the third trimester of gestation. Mummified fetuses within the same litter may be affected differently. In an outbreak situation with $C$. abortus, the abortion rate can exceptionally reach $60 \%$ in native flocks. ${ }^{46}$ One may assume that in these acute conditions, the number of mummified fetuses is probably much higher than in the endemic situation.

\section{Diagnosis}

Demonstration of placental lesions and isolation of the infectious agents are the principal requirements for making a definitive diagnosis. C. abortus, C. burnetii, and T. gondii affect mainly the placenta (placentitis), and very few lesions are actually observed on the fetus. Chlamydophila and Coxiella cause similar macroscopic changes in the cotyledonary areas of the placenta: white areas of necrosis and mineralization on the cotyledons. However, Coxiella infection also involves intercotyledonary areas. ${ }^{47}$ In border disease, the virus can be isolated from fetal blood (buffy coat). Serology studies and PCR detection of the organism in the placenta may also be used. However, one has to remember that when a female aborts as a result of an infectious agent, it may also shed other organisms at the same time, and that infection may occur without abortion (eg, C. burnetii). A Chlamydophila infection is suggested when elementary bodies are found in impression smears of trophoblast cells made from cotyledons or uterine discharge using Gimenez or modified Ziehl-Neelsen stains. ${ }^{44}$ In the case of Toxoplasma infection, the modified agglutination test can be used to detect antibodies in fetal and maternal serum. ${ }^{48}$

\section{Treatment}

There is no effective treatment available for Coxiella infection or border disease. For C. abortus, treatment with tetracycline or decoquinate in the last trimester reduces the incidence of abortion. For T. gondii infections, monensin throughout gestation may reduce the incidence of abortion. ${ }^{44}$ However, it should be remembered that no data are available for the overall incidence of fetal mummification in these diseases, and that such treatments have not yet been evaluated in controlled experiments.

\section{Prevention}

In most situations of ToxChBCox infection, culling does and ewes that have previously aborted is recommended, along with quarantining new animals before introducing them back into the herd. To prevent $C$. abortus, a vaccine can be administered, and animals should not be fed on the ground. To prevent toxoplasmosis, cats should not be allowed near pregnant females, and a vaccine is available in Europe and New Zealand. It is important to maintain good sanitary conditions and a monitoring program.

\section{Horses \\ Prevalence}

Fetal mummification in horses is very rare. An extensive study of abortion in the equine population of Michigan from 1985 to $1996(n=290)$ found only two cases $(0.007 \%)$ of fetal mummification. ${ }^{49}$ As is the case in cows, mummification occurs between the 3rd and 8th month of pregnancy, after the completion of ossification.

\section{Etiology}

In the rare reported cases, fetal mummification is associated with the death of a twin fetus. Usually the second fetus remains viable for a variable extended period of time, or until term if there is sufficient progesterone. The majority of surviving twin pregnancies abort at 9-11 months of gestation. ${ }^{50}$ The live fetus occupies most of the uterus, and its placenta maintains progesterone production and gestation. The other fetus (the future mummy) occupies only a small portion of one uterine horn. Eventually, the inadequate placental surface area compromises the fetus and leads to its death, most likely due to the fetus's increasing metabolic demands. Mummification of a single late-term fetus has been reported but is extremely rare, ${ }^{51}$ and no information was provided 
concerning the existence of a twin earlier in gestation. As is the case in cattle, the authors assumed an association between mummification and the maintenance of endogenous plasma levels of progesterone in the mare or the exogenous administration of progestins. ${ }^{10}$ However, placental and CL function, endometrial cup status, and hormonal profile were not documented, and exogenous progestins do not inhibit luteolysis in the mare.

Ultrasonography-guided twin reduction via a transvaginal (vesicular aspiration or fetal injection) or transabdominal (fetal cardiac injection) approach may result in mummification of the dead fetus. Other twin-reduction techniques, including craniocervical dislocation, may also potentially result in mummification of the dead fetus. ${ }^{52}$

\section{Clinical findings}

In mares, mummified fetuses are found unexpectedly during a normal pregnancy, dystocia during foaling or prolonged pregnancy. A mummified fetus is also sometimes expelled from an otherwise normal mare.

\section{Diagnosis}

Like the cow, the diagnosis of fetal mummification is uncomplicated and based on transrectal palpation and ultrasonography showing a hard and bony structure without fluid in the uterine lumen. The vaginal examination may reveal a slightly relaxed cervix with no vaginal discharge.

\section{Treatment}

As in cows, treatment is aimed at removing the mummified fetus from the uterus. Where elevated progesterone is associated with a CL, $\mathrm{PGF}_{2 \alpha}$ (25 mg dinoprost tromethamine IM) is indicated. In the absence of a CL, or if the mummy was not expelled following the initial treatment, the following can be used to relax the cervix and expel the mummified fetus: $17 \beta$-estradiol (5 mg IM) or $\mathrm{PGE}_{1}(200 \mu \mathrm{g}$ misoprostol) administered locally on or in the cervix 24 hours before oxytocin is administered. ${ }^{50}$ If the first treatment option fails, the cervix can be dilated mechanically and the mummified fetus removed manually from the uterus. Again, $17 \beta$-estradiol can be used 24 hours before mechanical cervical dilation. Should the medical approach to removing the mummy fail (eg, due to very large size), cesarean section may be required.

Whatever technique is used, uterine lavage to remove debris is indicated, along with a complete reproductive assessment of the mare in order to prescribe future uterine treatment. Based on the few case reports and contrary to the situation with cows, the prognosis for future fertility of the mare is still a topic of debate.

\section{Prevention}

Close monitoring to determine time of ovulation and so enable the diagnosis of double ovulation and confirm a twin pregnancy early on (day 14) is recommended. This allows for early twin reduction in order to optimize success, and minimizes the risk of fetal mummification, reduces the risk of twins, and optimizes the future fertility of the mare.

\section{Swine \\ Prevalence}

In swines, the prevalence of fetal mummification reported in the literature is variable. A prevalence of $3.45 \%$ has been found in Brazilian swine herds. ${ }^{53}$ Similar results $(3.9 \%)$ have been reported for French herds. ${ }^{54}$ Other studies have reported values of between $1.9 \%$ and $5.7 \%,{ }^{55}$ and $6.8 \%$ in gilts. ${ }^{56}$ An overall prevalence of $1.5 \%$ is probably accurate. ${ }^{57}$ This variation in prevalence estimates may be associated with differences between studies in how meticulously the placenta was examined and farrowing monitored.

\section{Etiology}

The mummification of fetuses is possible after days 35-40 of pregnancy, because the bones of the skeleton have formed. The causes of pregnancy loss, including fetal mummification, can be divided into two major classes. The first, which accounts for about $70 \%$ of losses, is related to animal-management practices, nutrition, and environmental factors. The second is infectious diseases, and accounts for about $30 \%$ of pregnancy losses.

Fetal mummification has been linked to parity, litter size, uterine capacity, temperature of the environment, presence of mycotoxins, and infectious diseases. ${ }^{56,57}$ Borges et al showed that larger litters (more than 12 piglets/litter) had a 14.5-fold-greater chance of presenting fetal mummification versus litters with fewer than ten piglets $(P<0.05) .{ }^{53}$ Le Cozler et al also found an increased probability of mummification with a lower average litter birth weight and size. ${ }^{54}$ This finding may be associated with a failure of the uterus to maintain a favorable environment for fetal growth and survival. ${ }^{58}$ There may also be a correlation with the placental production index (PPI; ratio of total fetal weight to total placental weight). Similar results were reported for the PPI, with 1.7-fold-higher odds of fetal mummification in sows with low PPI compared to those with high PPI $(P<0.05)$. As uterine length is similar between sows with versus without mummified fetuses, ${ }^{58}$ it 
is more likely that uterine space influences fetal death and eventually mummification, particularly in the last trimester of gestation, when fetal growth rate increases significantly. Interestingly, the odds ratios for having a mummy in the litter for sows with a parity of $0-1$ versus sows with a parity of 2-5 were 2.0 and 3.5 , respectively $(P<0.05)$. In primiparous sows, insufficient immunity (no vaccination program or exposure to endemic pathogens) may help explain these results. However, Borges et al took into account vaccination status and found no significant effect. ${ }^{53}$ Le Cozler et al did not observe any effect of parity on fetal mummification in their experiment. ${ }^{54}$ In general, the presence of one mummy in an otherwise normal litter may indicate physiological death, whereas the presence of multiple mummified fetuses raises the suspicion of an infectious cause of the reproductive failure..$^{59}$ The effect of the PPI in large litters on fetal mummification needs to be reviewed with current farm data.

As is the case for small ruminants, several viral diseases are associated with abortion and fetal mummification in swine (Table 3 ). The most common are porcine parvovirus (PPV) and porcine reproductive and respiratory syndrome virus (PRRSV). Because sows have several fetuses and the litter is infected transplacentally, these viruses spread within the uterus from one fetus to the other at different stages of gestation, resulting in a variety of responses within the litter, including reduced litter size, fetal mummification, and stillbirth. Note that PPV is considered to be enzootic. PRRSV kills fetuses mainly in the final trimester of pregnancy. ${ }^{60}$

\section{Clinical findings}

When the infection occurs early in gestation ( $<40$ days), PPV causes absorption of the infected fetuses, and the dam returns to estrus in a regular (18-24 days after heat) or irregular (25-38 days after heat) manner or fails to farrow. When the infection occurs later in gestation, litter size is reduced and the number of mummified fetuses increases,

Table 3 Infectious agents potentially associated with fetal mummification in swine

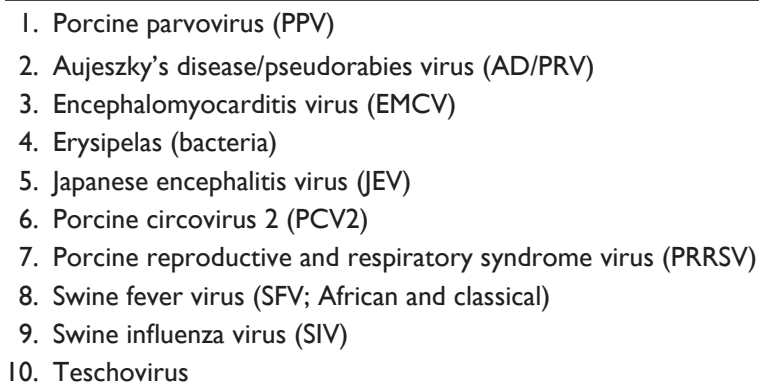

with no obvious maternal systemic clinical signs in either gilts or mature sows. Most sows become infected by their second pregnancy and develop permanent immunity. As a result, gilts and primiparous sows are more susceptible to PPV than mature sows. If infection occurs between 40 and 70 days of pregnancy, fetuses become infected sequentially, resulting in the mummification of fetuses of different sizes at birth, alongside the healthy piglets. If infected after 70 days of pregnancy, immunocompetent fetuses respond to PPV, and there is very little evidence of disease. ${ }^{59}$ There is no evidence of infection other than during gestation (reduced number of healthy piglets, mummification), and the economic loss is generally not significant on most farms.$^{60}$ The abortion rate is generally low with PPV, because mummified fetuses are delivered at term alongside the healthy piglets.

In the case of PRRSV, the clinical picture can vary from one farm to another. The better the health status of the herd, the less severe the effects of the disease. The acute clinical picture of the disease in a naïve herd is more evident. The sow may present loss of appetite, fever, cyanosis of the ears (5\%) and coughing. ${ }^{59}$ Most often, PRRSV kills fetuses after day 70 of pregnancy, and larger completely mummified or partially mummified fetuses are seen in the course of the disease, in addition to stillbirth, weak piglets, and early farrowing (days 100-116). ${ }^{60}$

\section{Diagnosis}

The number of mummified fetuses relative to litter size and age at which death occurs is an indication of the potential etiologic agent. The approximate age of death of the mummified fetus can be determined by using the following equation: age in days of the mummy = (length of the mummy from crown of head to rump in millimeter/3) +21 . If the problem is insufficient space or a large litter, a review of the records would reveal mummified fetuses associated with a normal litter size (eg, one mummy with 14 live piglets). If the problem is an infectious agent, the litter size will be normal, but more mummified fetuses and less live piglets will be observed (eg, litter size of 12 with six live piglets, two dead piglets, and four mummified fetuses) ${ }^{60}$

When litters are small and multiple-size mummies are observed in unvaccinated primiparous sows, PPV infection is at the top of the list of suspected causes. A paired serum sample showing a significant increase in antibody levels is associated with PPV infection. However, serology may not help, because many sows come back positive but are normal. Sampling the blood of piglets before they have suckled may be more helpful for the diagnosis. Submitting 
a mummified fetus less than $15 \mathrm{~cm}$ in length for fluorescent antibody tests will confirm the diagnosis. ${ }^{61}$ When all mummies are the same size, mycotoxins should be considered as a possible cause. Where large mummified fetuses occur late in pregnancy (after day 70 of gestation), PRRSV would be suspected, as the virus kills fetuses more often in late gestation. In addition to clinical history, serology (fluorescent antibody test or enzyme-linked immunosorbent assay) in a herd that has not been previously exposed to PRRSV provides a reliable diagnosis. In the early acute phase, PCR tests on blood will be able to detect viral DNA. ${ }^{60}$ There are no pathognomonic gross or microscopic lesions in the case of PRRSV infection.

\section{Treatment}

In a large population, the best treatment is prevention.

\section{Prevention}

Regardless of the housing situation used, proper care/comfort, optimal nutrition, effective stress management, rigorous sanitary protocols, and preventive medicine (vaccination) are all of paramount importance. The management program should monitor feeding intake, ventilation, and temperature. Individual and group housing both have unique sources of potential stress that need to be minimized. PPV infection can be controlled by ensuring good immune status in females and males before breeding. All gilts should be naturally infected or vaccinated (two injections, 1 month apart) with PPV vaccine before breeding. PRRSV causes a chronic and persistent infection that is not a function of age (young or adult) or whether or not the swine is exposed to the virus in the uterus. Farmers should determine if the herd has been exposed to PRRSV by serology. If the herd is negative, the farmer needs to purchase stock and semen from negative herds and establish a rigorous sanitary and biosecurity program (eg, provide boots, coveralls, prohibit the borrowing of equipment, quarantine affected animals). If the herd is positive, farms have to accept a decrease in farrowing of about $15 \%$. Vaccination (live or killed) of new animals, both gilts and boars, in isolation, and acclimatization for at least 6 weeks is needed. Note that the vaccine has to match the type of PRRSV present on the farm. The farmer should reduce culling to increase the mating program to compensate for the $15 \%$ reduction in farrowing and buy only gilts from infected herds.

\section{Dogs}

\section{Prevalence}

As is the case in swine, goats, and sheep, pregnancy loss due to fetal mummification in dogs is associated with infectious causes. In dogs, the most common cause is canine herpesvirus (CHV). Serologic surveys in domestic dogs have shown a prevalence of $30 \%-100 \%$ in some kennels. ${ }^{62}$ Although fetal mummification has been described in dogs, there are no accurate figures for incidence, although it is assumed to be very low.

\section{Etiology}

Both CHV and other herpesvirus cause a lifelong latent infection. Virus reshedding occurs sporadically when animals are immunosuppressed or unduly stressed (eg, pregnancy, transport, or adoption). The $\mathrm{CHV}$ infection associated with fetal mummification occurs via transplacental transmission in utero, although newborn puppies can acquire CHV from passage through the birth canal, contact with infected littermates, or contact with oronasal secretions of the dam. ${ }^{62}$ The effects of transplacental infection with CHV depend on the stage of gestation at which infection occurs. One study showed that inoculating bitches intravenously with CHV during the second trimester (between days 30 and 40 of gestation) induced fetal mummification and the abortion of live puppies, whereas inoculation between days 47 and 53 of gestation resulted in the delivery of live infected puppies at term. ${ }^{63-65}$ A definitive diagnosis requires pathognomonic signs of vasculitis in abdominal organs or virus isolation from infected puppies. Other infectious (canine PV type 1, Toxoplasma) or noninfectious causes, such as hypothyroidism ${ }^{61}$ and chromosome abnormalities, ${ }^{65}$ may also cause fetal loss, although their association with fetal mummification does not seem to be well documented.

\section{Clinical findings}

Early pregnancy infection is revealed as a case of infertility (fetus is resorbed). Mid- to late-pregnancy infection can result in either the abortion of fetuses with different degrees of mummification, dead fetuses, stillborn fetuses, or weak newborn puppies, all with no clinical signs in the bitch. In the case of abortion with or without mummified fetuses, a diagnosis may be difficult, especially if the bitch consumes or hides the fetuses. ${ }^{66}$ In postnatal infection, puppies contract an acute and fatal illness, usually between 1 and 3 weeks of age, with discomfort on abdominal palpation, weight loss, and depressed demeanor.

\section{Diagnosis}

Diagnosing CHV infection is based on information from the clinical history of the bitch and her kennel, physical examination, and characteristic pathologic changes seen in affected puppies, including fetal mummification. 


\section{Treatment}

No effective treatment has been reported.

\section{Prevention}

For kennels exhibiting this problem, an inactivated vaccine is licensed for use in some European countries (Eurican Herpes 205; Merial, Lyon, France) for administration 10 days postcoitus and 6 weeks later in bitches. ${ }^{61}$ Eradication of $\mathrm{CHV}$ from kennels and screening for infected animals are often impractical. Cesarean delivery or artificial insemination (even of a suspected carrier male) have been proposed as a way of reducing the spread of infection, although the benefits of such recommendations have not been clearly demonstrated and additional controlled studies are needed. Therefore, breeders should reduce environmental stressors for the bitch and puppies, and maintain a warm temperature during birth and thereafter for newborn puppies while avoiding dehydration.

\section{Cats \\ Prevalence}

In cats, pregnancy loss may occur at any stage of gestation, and may be manifested by embryonic/fetal resorption, abortion of fetuses, stillbirth, and/or fetal mummification. ${ }^{62}$ However, cats are more similar to cattle or horses in that fetal mummification is sporadically reported and incidental. Although fetal mummification and fetal retention, either in or ex utero, have been described in cats, the actual incidence is unknown and presumed to be low.

\section{Etiology}

The presence of mummified fetuses outside the uterus has been reported in queens, ${ }^{67,68}$ and is associated with trauma leading to uterine rupture. ${ }^{69,70}$ Such viruses such as feline panleukopenia virus, feline leukemia virus, feline rhinotracheitis, and feline infectious peritonitis have been associated with not only abortion, stillbirth, and neonatal death but also fetal mummification. ${ }^{71-73}$ However, only feline panleukopenia has been shown to cross the placental barrier. $^{74}$

\section{Clinical findings}

As clinical signs of illness are usually absent in queens, mummified fetuses are usually an incidental discovery during ovariohysterectomy or other abdominal surgery. Mummified fetuses appear encapsulated within uterine tissue, wrapped in omental adhesions, or free in the peritoneal cavity beyond the normal time of parturition following normal birth or dystocia.

\section{Diagnosis}

Extrauterine mummified fetuses have been accidentally found in the abdominal cavity by ultrasound and radiography, and during abdominal surgery. ${ }^{62,69,70}$

\section{Treatment}

The current treatment approach is surgical removal of the mummies.

\section{Prevention}

As is the case for cows, due to the absence of specific causes associated with fetal mummification, it is important to maintain good sanitary conditions and a vaccination program. A rigorous reproductive monitoring program is essential.

\section{Discussion}

Fetal mummification is diagnosed occasionally in all major domestic species, and occurs most often in multiparous and polytocous animals. It is much less prevalent in monotocous species. While some authors give a prevalence estimate for fetal mummification, for most species and situations this is very difficult for a variety of reasons: few samples are ever submitted for analysis, the routine tests performed for cases of abortion situation (eg, serology) are not specific, mummified tissues are very difficult to study and are often not sent to the laboratory, most reports on gestation losses do not distinguish mummies from normal aborted fetuses, females with mummified fetuses are usually asymptomatic, and the condition is generally sporadic in nature.

Both infectious and noninfectious causes have been associated with fetal mummification, and these causes may overlap and be interrelated. The involvement of an infectious agent is more evident in some species (small ruminants, dogs, and swine) than others (horses, cattle, and cats). In addition to the difficulties associated with estimating the prevalence of fetal mummification, studying the phenomenon of fetal mummification is also complicated for a number of other reasons: different infectious agents with different tropisms (placenta versus fetus), species differences in length of gestation, and our lack of knowledge about the minimal times necessary for intrauterine mummification. Based on natural mummification processes, it is reasonable to assume that the affected fetus must be well advanced in its development (ie, have bones); otherwise, all tissues would degrade into their constituent elements and be absorbed at the same time as uterine and fetal fluids or expelled when the cervix relaxes and opens.

The exact mechanism responsible for intrauterine mummification is not known. One study hypothesized that 
intrauterine mummification of the cow fetus occurs before keratinization of the skin. ${ }^{75}$ Instead of the normal autolysis of tissue, there is an imbalance in fluid flow across the skin and faster dehydration of the body. Between days 77 and 200 of gestation, the cow fetus's hair follicles and canals form, and the skin gradually keratinizes and becomes thicker, blocking the fluid flow across the skin. ${ }^{76}$ The available data for gestation length show that fetal mummification most often occurs at the end of the second or beginning of the third trimester in most species, which coincides with pre-skin keratinization. The absence of keratinization would facilitate the fluid flow across the skin. This could explain why fetal mummification is independent of the length of gestation (70 days in the bitch, 350 days in the mare). However, the exact time of fetal death and degree of mummification have never been determined with precision.

The key event behind the intrauterine mummification process is the dehydration of the fetus and annex membranes, which neutralizes the autolysis of tissues in the absence of oxygen and bacteria. Studies indicate that the amniotic fluid is regulated by variation in the rate of intramembranous absorption across the network of blood vessels (capillaries) located on the opposite side of the fetal surface of the amnion. ${ }^{77,78}$ Studies have shown that intramembranous absorption is unidirectional in nature (from amniotic chamber to fetal blood), and that transport across the amnion occurs at the same rate in both directions. ${ }^{79}$ Furthermore, transport across the amnion occurs at the same rate in both directions for small- and medium-molecularweight solutes. ${ }^{79}$ Intramembranous permeability allows the different-size molecules technetium-99m pertechnetate and ${ }^{14} \mathrm{C}$-insulin to be transported two and four times faster outward from the amniotic fluid, respectively. Faber and Anderson reported a similar effect with radiolabeled albumin. ${ }^{80}$ This intramembranous absorption capacity increases with age of gestation. ${ }^{81}$ Based on these preliminary data, one may hypothesize that at the end of the second trimester and beginning of the third trimester of gestation, the low degree of keratinization of the skin of the dead fetus leads to a more rapid loss of body fluid into the amniotic chamber. The amniotic fluid is then rapidly reabsorbed by the intramembranous capillaries and returned to umbilical circulation, and eventually to the mother. Further characterization of this exchange mechanism is certainly needed. Other questions remain unanswered, like the role of progestogens or the presence of a functional CL in monotocous females with mummified fetuses, a situation that is very different from polytocous species.
In horses, cats, and cattle, fetal mummification would appear to be an incidental event that does not impact the future fertility of the dam. Given that case reports are rare, the long-term fertility of dams following fetal mummification is difficult to evaluate in cats and mares. In swine and small ruminants, an infectious agent appears to be an important cause of fetal mummification. In large populations, the longterm fertility of females with mummified fetuses is difficult to assess, because females are often culled, as recommended by current herd-management practices. Note that most of the infectious agents mentioned have a tropism for the placenta, causing placentitis and potentially compromising future female fertility if not treated properly.

As little is known about the different aspects of fetal mummification, proper management and sanitary protocols as well as preventive medicine (vaccination) are all of paramount importance in species where infectious agents are common (swines, small ruminants, dogs). For monotocous species (cattle and horses), preventive medicine is also important, although an individual approach based on the specific characteristics of the species is also key to returning the female to acceptable fertility after the mummy is removed.

\section{Conclusion}

Fetal mummification is very different in terms of etiology, clinical signs, treatment, prognosis, and preventive approaches for monotocous versus polytocous species. More scientific knowledge is needed to increase diagnostic efficiency and precision, and to allow for better treatment and the establishment of preventive programs aimed at preserving overall fertility.

\section{Disclosure}

The author reports no conflicts of interest in this work.

\section{References}

1. Barth AD. Induced abortion in cattle. In: Morrow DA, editor. Current Therapy in Theriogenology. 2nd ed. Philadelphia: WB Saunders; 1986: 205-208.

2. Hailat NQ, Lafi SQ, Al-Darraji A, Al-Ani F, Fathalla M. Ovine fetal maceration. Small Anim Res. 1997;25:89-91.

3. Tutt CL. Postpartum mummification of a co-twin fetus in a Cameroon dwarf goat doe. Vet Rec. 1997;140:229-231.

4. Meyers PJ, Varner DD. Abortion of a mummified fetus associated with short uterine body in a mare. J Am Vet Med Assoc. 1991;198: 1768-1770.

5. Christianson WT. Stillbirths, mummies, abortions, and early embryonic death. Vet Clin North Am Food Anim Pract. 1992;8:623-639.

6. Johnston SD, Raksil S. Fetal loss in the dog and cat. Vet Clin North Am Small Anim Pract. 1987; 17:535-554.

7. Kennedy PC, Miller RB. The female genital system. In: Jubb KV, Kennedy PC, Palmer N, editors. Pathology of Domestic Animals. Vol 3. 4th ed. New York: Academic; 1993:387-470. 
8. Janaway RC, Wilson AS, Caprio Díaz G, Guillen S. Taphonomic changes to the buried body in arid environments: an experimental case study in Peru. In: Ritz K, Dawson L, Miller D, editors. Criminal and Environmental Soil Forensics. New York: Springer; 2008:341-356.

9. Drost M. Complications during gestation in the cow. Theriogenology. 2007;68:487-491.

10. Barder JA, Troedsson MH. Mummified fetus in a mare. J Am Vet Med Assoc. 1996;208:1438-1440.

11. Arthur GH, Noakes DE, Pearson H, Parkinson TJ. Infertility in the sow and gilt. In: Noakes AD, editor. Veterinary Reproduction and Obstetrics. 7th ed. London: WB Saunders; 1996:468-496.

12. Threfall WR. Singleton mummified fetus in a Standardbred mare. Equine Vet Ed. 2005;17:235-238.

13. Khan CK, Salam A. The mystery of mummification in equines. Indian Vet J. 1967;44:338-344.

14. Finocchio EJ, Steinmeyer PE. Mummification of an equine fetus. Vet Med Small Anim Clin. 1972;67:192.

15. DiPietro AJ, Turner TM, Lock TF, Williams RG. Retain twin fetus in a mare. J Am Vet Med Assoc. 1983;7:800.

16. Sandoval-Castillo J, Villavicencio-Garayzar C. Fetal mummification in silky shark (Carcharhinus falciformis) from the Gulf of California, Mexico. Braz Arch Biol Technol. 2008;51:551-554.

17. Roberts SJ. Disease and accidents of the gestation period. In: Veterinary Obstetric and Genital Diseases. 3rd ed. Newton Abbot, UK: David and Charles; 1986:123-144.

18. Johnson WH, Manns JG, Adams WN, Mapletoft RJ. Termination of pregnancy with cloprostenol and dexamethasone in intact or ovariectomized cows. Can Vet J. 1981;22:288-290.

19. Roberts SJ. The enigma of fetal mummification. J Am Vet Med Assoc. 1962;140:691-698.

20. Ghanem ME, Suzuki T, Akita M, Nishibori M. Neospora caninum and complex vertebral malformation as possible causes of bovine fetal mummification. Can Vet J. 2009;50:389-392.

21. Mahajan M, Sharma A. Haematic mummification due to umbilical cord torsion in a cow: a case report. Ind Vet J. 2002;79:1186-1187.

22. Moore AA, Richardson GF. Uterine torsion and fetal mummification in a cow. Can Vet J. 1995;36:705-706.

23. Irons PC. Hysterotomy by a colpotomy approach for treatment of foetal mummification in a cow. J S Afr Vet Assoc. 1999;70:127-129.

24. Stevens RW, King GJ. Genetic evidence for a lethal mutation in Holstein-Friesian cattle. J Hered. 1968;59:366-368.

25. Elmore RG. Focus on bovine reproductive disorders: managing cases of fetal mummification. Vet Med. 1992;87:155-159.

26. Ghanem ME, Nakao T, Nishibori M. Deficiency of uridine monophosphate synthase (DUMPS) and X-chromosome deletion in fetal mummification in cattle. Anim Reprod Sci. 2006;1:45-54.

27. Shanks RD, Dombrowski DB, Harpestad GW, Robinson JL. Inheritance of UMP synthase in dairy cattle. J Hered. 1984;75:337-340.

28. Done JT, Terlecki S, Richardson C, et al. Bovine virus diarrhea mucosal disease virus: pathogenicity for the fetal calf following maternal infection. Vet Rec. 1980;106:473-479.

29. Lefebvre RC, Saint-Hilaire E, Morin I, Couto GB, Francoz D, Babkine M. Retrospective case study of fetal mummification in cows that did not respond to prostaglandin F2 treatment. Can Vet J. 2009;50: 71-76.

30. Wenkoff MS, Manns JG. Prostaglandin-induced expulsion of bovine fetal mummies. Can Vet J. 1977; 18:44-45.

31. Frazer GS. Obstetrics Part 1. Pregnancy complications in the cows. Poster presented at: Proceedings of the North American Veterinary Conference; January 17-21; Orlando, FL.

32. Vandeplassche M, Bouters R, Spincemaille J, Bonte P. Induction of parturition in cases of pathological gestation in cattle. Theriogenology. 1974;1:115-121.

33. Hirshbrunner G, Kaufmann C. Dix cas de foetus momifiés traités avec des PGE2. Point Vet. 2005;260:64-66.

34. Seguin BE. Role of prostaglandins in bovine reproduction. J Am Vet Med Assoc. 1980;176:1178-1181.
35. Stolla R, Schmid G. Auswirkungen natürlicher und synthetischer PGF2 $\alpha$-präparate auf die uteruskontraktilität des Rindes. Berl Munch Tierarztl Wochenschr. 1990;103:198-202.

36. Hirsbrunner G, Knutti B, Küpfer U, Burkhardt H, Steiner A. Effect of two dosages of d-cloprostenol on intrauterine pressure and uterine motility during diestrus in experimental cows. Zentralbl Veterinarmed A. 1999;46:345-352.

37. Hirsbrunner G, Eicher R, Küpfer U, Burkhardt H, Steiner A. Effect of different doses of prostaglandin E2 on intrauterine pressure and uterine motility during diestrus in experimental cows. Theriogenology. 2000;54: 291-303.

38. Hirsbrunner G, Knutti B, Küpfer U, Burkhardt H, Steiner A. Effect of prostaglandin E2, DL-cloprostenol, and prostaglandin E2 in combination with $\mathrm{D}$-cloprostenol on uterine motility during diestrus in experimental cows. Anim Reprod Sci. 2003;79:17-32.

39. Carson RL, Wolfe DH, Klesius PH, Kemppainen RJ, Scanlan CM. The effects of ovarian hormones and ACTH on uterine defense to Corynebacterium pyogenes in cows. Theriogenology. 1988;30:91-97.

40. Wira CR, Sandoe CP. Hormonal regulation of immunoglobulins: influence of estradiol on immunoglobulins $\mathrm{A}$ and $\mathrm{G}$ in the rat uterus. Endocrinology. 1980;106:1020-1026.

41. Hopper R, Hostetler D, Smith J, et al. Surgical removal of a mummified fetus via colpotomy. Bovine Pract. 2006;40:57-58.

42. Wolfe DF, Riddell MG, Mysinger PW, et al. A caudal flank approach for the collection of oviductal-stage bovine embryos. Theriogenology. 1990;34:167-174.

43. Boileau M, Babkine M, Desrocher A. Effet de la rotidrine sur le myomètre lors de manipulations obstétricales chez la vache. Med Vet Que. 2001;31:190-191.

44. Edmondson MA, Roberts JF, Baird AN, Bychawski S, Pugh DG. Theriogenology of sheep and goats. In: Pugh DG, Baird AN, editors. Sheep and Goat Medicine. 2nd ed. Maryland Heights (MO): Elsevier Saunders; 2012:150-230.

45. Braun WF Jr. Noninfectious prenatal pregnancy loss in the doe. In: Youngquist RS, Threlfall WR, editors. Current Therapy in Large Animal Theriogenology. 2nd ed. Philadelphia: WB Saunders; 2007: 555-561.

46. East E. Chlamydiosis. In: Morrow DA, editor. Current Therapy in Theriogenology. 2nd ed. Philadelphia: WB Saunders; 1986: 609-610.

47. Moeller RB. Cause of caprine abortion: diagnosis assessment of 211 cases (1919-1998). J Vet Diagn Invest. 2001;13:265-275.

48. Dubey JP. Diagnosis of livestock abortion due to Toxoplasma gondii. In: Kirkbride CA, editor. Laboratory Diagnosis of Livestock Abortion. 3rd ed. Ames (IA): Iowa State University Press; 1990:150-157.

49. Tengelsen LA, Yamini B, Mullaney TP, et al. A 12-year retrospective study of equine abortion in Michigan. J Vet Diagn. 1997;9:303-306.

50. Card CE. Fetal maceration and mummification. In: McKinnon AO, Squires EL, Vaala WL, Varner DD, editors. Equine Reproduction. 2nd ed. Ames (IA): Blackwell; 2011:2373-2375.

51. Newcombe JR, Wilson MC. Mummified singleton foetus in a mare. Aust Equine Vet. 1998;16:33-34.

52. Wolfsdorf KE. Management of postfixation twins in mares. Vet Clin $N$ Am Equine. 2006;22:713-725.

53. Borges VF, Bernardi ML, Bortolozzo FP, Wentz I. Risk factors for stillbirth and foetal mummification in four Brazilian swine herds. Prev Vet Med. 2005;70:165-176.

54. Le Cozler Y, Guyomarch C, Pichodo X, Quinio PY, Pellois H. Factors associated with stillborn and mummified piglets in high-prolific sows Anim Res. 2002;51:261-268.

55. Schneider JF, Rempel LA, Rohrer GA. Genome-wide association of swine farrowing traits. Part I: Genetic and genomic parameter estimates. J Anim Sci. 2012;90:3353-3360.

56. Van de Lande T, Van Rens BT. Critical periods for foetal mortality in gilts identified by analyzing the length distribution of mummified foetuses and frequency of non-fresh stillborn piglets. Anim Reprod Sci. $2003 ; 75: 141-150$. 
57. Dial GD, Marsh WE, Polson DD, Vaillancourt JP. Reproductive failure: differential diagnosis. In: Leman AD, Straw BE, Mengeling WL, D'Allaire S, Taylor DJ, editors. Diseases in Swine. 7th ed. Ames (IA): Iowa State University Press; 1992:88-137.

58. Wu MC, Hentzel MD, Dziuk PJ. Effect of stage of gestation, litter size and uterine space on the incidence of mummified fetuses in pigs. J Anim Sci. 1988;66:3202-3207.

59. Sims LD, Glastonbury JR. Neonatal mortality. In: Sims LD, Glastonbury JR, editors. The Pathology of the Pig: A Diagnostic Guide. Barton, Australia: Pig Research and Development; 1996:423-432.

60. Zimmerman J, Benfield DA, Murtaugh MP, et al. Porcine reproduction and respiratory syndrome virus (porcine arterivirus). In: Straw BE, Zimmerman JJ, D’Allaire S, Taylor DJ, editors. Diseases of Swine. 9th ed. Oxford: Blackwell; 2006:387-418.

61. Muirhead MR, Alexander TJL. Reproduction: non-infectious infertility. In: Carr J, editor. Managing Pig Health. 2nd ed. Sheffield: 5m; 2013: 159-198.

62. Greene CE. Canine herpesvirus infection. In: Greene CE, editor. Infectious Diseases of the Dog and Cat. 4th ed. St Louis: Elsevier Saunders; 2012:48-54.

63. Johnston SD, Kustritz MV, Olson PNS. Canine pregnancy. In: Johnston SD, Kustritz MV, Olson PN, editors. Canine and Feline Theriogenology. Toronto: WB Saunders; 2001:150-176.

64. Hashimoto A, Hirai K, Suzuki Y, et al. Experimental transplacental transmission of canine herpesvirus in pregnant bitches during the second trimester of gestation. Am J Vet Res. 1983;44:610-614.

65. Hashimoto A, Hirai K, Yamaguchi T, et al. Experimental transplacental infection of pregnant dogs with canine herpesvirus. Am J Vet Res. 1982;43:844-850.

66. Johnston SD, Buoen LC, Weber AF, et al. Triploidy (117, XXX) in a stillborn canine pup conceived with frozen semen. JAm Vet Med Assoc. 1989;194:1446-1448.

67. Post K. Embryo and fetal loss in the canine: a review. In: Theriogenology Handbook. Hastings (NE): Society for Theriogenology; 1995:1-120.

68. Vasseur PB, Feldman EC. Pyometra associated with extrauterine pregnancy in cat. J Am Anim Hosp Assoc. 1982;18:872-874.
69. Johnston SD, Harish G, Stevens JB, Scheffler HG. Ectopic pregnancy with uterine horn encapsulation in a cat. J Am Vet Med Assoc. 1983;183(9):1001-1002.

70. Carrig CB, Gourley IM, Philbrick AL. Primary abdominal pregnancy in a cat subsequent to ovariohysterectomy. J Am Vet Med Assoc. 1972;160: 308-310.

71. Crownover RW, Yeargen GS. Extrauterine pregnancy in a spayed cat. Vet Med Small Anim Clin. 1976;71:1698-1699.

72. Cotter SM, Hardy WD, Essex M. Association of feline leukemia virus with lymphosarcoma and other disorders in the cat. JAm Vet Med Assoc. 1976;166:1698-1699.

73. Scott FW, Weis RC, Post JE, et al. Kitten mortality complex (neonatal FIP?). Feline Pract. 1979;9:44-56.

74. Johnston SD, Raksil S. Fetal loss in the dog and cat. Vet Clin N Am Small Anim. 1987;17:535-554.

75. Scott FW, Geissinger C, Peltz R. Kitten mortality survey. Feline Practice 1978;8:31-34.

76. Hubbert WT. Relationship of unkeratinized skin to bovine fetal mummification: an hypothesis. Can Comp Med. 1974;38:203-206.

77. Lyne AG, Heideman MJ. The prenatal development of skin and hair in cattle (Bos taurus). Aust J Biol. 1959;12:72-95.

78. Daneshmand SS, Cheugn CY, Brace RA. Regulation of amniotic fluid volume by intramembranous absorption in sheep: role of passive permeability and vascular endothelial growth factor. Am J Obstet Gynecol. 2003;188:786-793.

79. Mann SE, Lee JJ, Ross MG. Ovine intramembranous pathway permeability: use of solute clearance to determine membrane porosity. J Matern Fetal Med. 2001;10:335-340.

80. Faber JJ, Anderson DF. Regulatory response of intramembranous absorption of amniotic fluid to infusion of exogenous fluid in sheep. Am J Physiol. 1999;277:236-242.

81. Adams EA, Choi HM, Cheung CY, Brace RA. Comparison of amniotic and intramembranous unidirectional permeabilities in late-gestation sheep. Am J Obstet Gynecol. 2005;193:247-255.
Veterinary Medicine: Research and Reports

\section{Publish your work in this journal}

Veterinary Medicine: Research and Reports is an international, peer-reviewed, open access journal publishing original research, case reports, editorials, reviews and commentaries on all areas of veterinary medicine. The manuscript management system is completely online and includes a very quick and fair peer-review system.

\section{Dovepress}

Visit http://www.dovepress.com/testimonials.php to read real quotes from published authors. 